\title{
Evaluation of Neuropharmacological Effects of Different Chemical Extracts of Flemingia Stricta (Roxb.) Leaves.
}

Md. Shahrear Biozid $\dagger$, Mohammad Nazmul Alam†*, Md. Jainul Abeden $\dagger$, Md. Masudur Rahman, Md. Rafikul Islam.

Department of Pharmacy, International Islamic University Chittagong, Kumira, Chittagong, Bangladesh.

$\dagger$ Authors contributed equally.

*Corresponding Author E-mail: nazmul_pharmacy@yahoo.com

\begin{abstract}
Background: Traditional preparation of the leaf of Flemingia stricta (Fabaceae) Roxb. , a medicinal plant of the Indian subcontinent, has been used for treatment of different diseases as herbal preparation. Our purpose was to analyze Neuropharmacological effects of different chemical extracts of Flemingia stricta Roxb. as particular form of behavioral inhibition that occurs in response to novel environmental events.
\end{abstract}

Methods: In present study, the anxiogenic activity of crude extracts of Flemingia stricta leaves was determined using standard animal behavioral models, such as hole cross and open field; Sedative property and anxiolytic potential were assessed by conducting thiopental sodium induced sleeping times tests and elevated plus maze test respectively.

Results: The crude extracts at both dose $(200$ and $400 \mathrm{mg} / \mathrm{kg})$ exhibited a significant $(\mathrm{P}<0.05$, $\mathrm{P}<0.01)$ dose-dependent suppression of motor activity and exploratory activity of mice in both open field and hole cross test. In anxiolytic study, extracts displayed increased percentage of entry into open arm at the dose of 200 and $400 \mathrm{mg} / \mathrm{kg}$. Extracts produced a significant $(\mathrm{P}<0.05$, $\mathrm{P}<0.01)$ increase in sleeping duration and reduction of onset of sleep compared to sodium thiopental at both doses $(200$ and $400 \mathrm{mg} / \mathrm{kg})$.

Conclusion: This study demonstrates that the treated extracts have significant central nervous system depressant effect. Further studies on the active constituent of the extract can provide approaches for therapeutic intervention.

\section{Keywords}

Flemingia stricta, Sedative, Elevated plus maze, Anxiolytic, CNS-depressant, Locomotor activity, Neuropharmacology. 


\section{Background}

Presently herbal drugs are wide-spoken as green medicine for their safe and trustworthy health care paradigms. Traditional herbal medicines a rising interest since a couple of decades due to their incredible pharmacological activities, economic viability and less side effects in different healthcare managements rather than other systems [1]. Anxiety and depression are the most common psychiatric disorders; already cover $20 \%$ of the adult population, suffering from these illnesses at some time during their lives [2-4]. It has grown up to be an important area of research interest in psychopharmacology during this decade [5].

Drugs acting on the central nervous system (CNS) are still the most widely used pharmacological agents [6]. Benzodiazepines are among the most prescribed and effective anti-anxiety drugs used worldwide [7]. Barbiturates and Ethanol are also frequently used. Both barbiturates and benzodiazepines show their CNS effect by interaction with postsynaptic gamma aminobutyric acid receptor $\left(\mathrm{GABA}_{\mathrm{A}}\right.$ receptor) [8]. The most serious shortcoming of barbiturates as a depressant is linked to their narrow margin of safety, and only 10 times of their therapeutic dose may be lethal [9]. Moreover barbiturates can grow both psychological and physiological dependence $[10,11]$. Benzodiazepines are the most commonly used CNS depressant which lead to tolerance and physical dependence, for example diazepam typically produces sedation at dose of 5 to $10 \mathrm{mg}$ in user of first time, but those who repeatedly use it may become tolerant to doses of several hundred milligrams [12]. Ethanol produces its depressant action by changing membrane fluidity and interaction with the GABA system [9, 13]; also it has a tolerance and physical dependence activity. Statistically it has been showed; alcohol addiction in American society is $5 \%$ to $10 \%$ for men and $3 \%$ to $5 \%$ for women [14]. A natural CNS depressant with minimum or no toxicity is therefore, essential.

Flemingia stricta (Fabaceae) Roxb. is an erect subshrub, distributed in the Southeast Asian country such as- Bangladesh, Bhutan, China, India, Indonesia, Laos, Myanmar, Philippines, Thailand and Vietnam [15, 16]. In Bangladesh, it is available in Chittagong, Chittagong Hill Tracts and Sylhet. It is known as Charchara (in Bangla) and Krangdunaduepay, Sai Kheu (Marma); Keramkana(Tripura); Tamatamaking (Khumi) and Harsanga, Khaskura, Uskura (Chakma) in local tribes of Chittagong, Bangladesh[17]. Flemingia stricta is used by Chakma healers for treatment of polio. The species is also used to treat rheumatism followed by bone fracture, cough, asthma, goiter, urinary problems, snake bite, insect bite, leprosy, tumor and cancer, caries, hysteria, tuberculosis, insomnia and intestinal worms [18-20].

According to the literature review on this plant, it showed that the plant has been used as traditional medicine for the treatment of various diseases for many years. Therefore, we undertook the study to assess the neuropharmacological potential of $F$. stricta leaves, by using 
different animal models and studying the effect of the different chemical plant extracts on their exploratory behavior.

\section{Methods}

\section{Plant collection and identification}

Whole plants of $F$. stricta were collected from Bhatiary, Chittagong region, Bangladesh. The plants were identified by Dr. Shaikh Bokhtear Uddin, Taxonomist and Professor, Department of Botany, University of Chittagong, Chittagong, Bangladesh.

\section{Preparation and extraction of leaf extract}

The collected leaves were thoroughly washed with distilled water and dried under the shade. The dried sample was coarsely powdered (500 g) and extracted with methanol for 3 days to allow total extraction process. After that the plant extract was filtered with sterilized cotton filter and the filtrate was gathered in a beaker. The plant extracts then kept in a water bath at $60{ }^{\circ} \mathrm{C}$ to evaporate the solvent from the solution. The container allowed to airtight for $72 \mathrm{~h}$ and filtrate thus obtained was concentrated by using a rotary evaporator. The extract was divided into two portions. One portion ( $2.5 \mathrm{~g}$ ) was poured into glass vials to be tested as crude methanol extract, whereas the second portion ( $8 \mathrm{~g}$ ) was dissolved in concentrated methanol and partitioned successively into four different extractives [21]. The fractions were then concentrated using a rotary evaporator which results ethyl acetate fraction (yield weight $1.50 \mathrm{~g}$ ), chloroform fraction (yield weight $1.25 \mathrm{~g}$ ), petroleum ether fraction (yield weight $2.15 \mathrm{~g}$ ) and aqueous fraction (2.75g).

\section{Animal}

Male Swiss albino mice, 3-4 weeks old, weighing between 20-25g, were collected from the International Center for Diarrheal Disease and Research, Bangladesh. Animals were maintained under standard environmental conditions [temperature: $(24 \pm 1){ }^{\circ} \mathrm{C}$, relative humidity: $55 \%-65 \%$ and $12 \mathrm{~h}$ light/12 $\mathrm{h}$ dark cycle] and had free access to feed and water ad libitum. Prior to experimentation, animals were familiarized in laboratory condition for one week.

\section{Acute toxicity study}

Mice were divided into control and test groups $(n=5)$. The test groups received the extract per orally at the doses of 600,800 and $1000, \mathrm{mg} / \mathrm{kg}$. Then the animals were kept in separate cages and were allowed to food and ad libitum. The animals were observed for possible behavioral changes, allergic reactions and mortality for the next $72 \mathrm{~h}$ [22].

\section{Neuropharmacological tests}

The study was done to find out if extracts had any effect on the central nervous system. Effect on exploratory behavior of mice was evaluated by hole cross test and open field test. Elevated plus 
maze test was conducted for determination of anxiolytic activity whereas thiopental sodium induced sleeping time test was for sedative activity.

\section{Open field test}

The method was adopted as described by Gupta et al [22]. In the open field test, the animals were divided into control, positive control and test groups containing 5 mice each. The test groups received extract of $F$. stricta at the doses of 200 and $400 \mathrm{mg} / \mathrm{kg}$ body weight orally whereas the control group received the vehicle (1\% Tween 80 in water). The floor of half square meter open field was divided into a series of squares each alternatively colored black and white. The apparatus had a $40 \mathrm{~cm}$ height walls. The number of squares traveled by the animals was counted for $5 \mathrm{~min}$ at $0,30,60,90,120 \mathrm{~min}$ after oral administration of both doses of the extract.

\section{Hole cross test}

The apparatus was a cage of $30 \mathrm{~cm} \times 20 \mathrm{~cm} \times 14 \mathrm{~cm}$ with a steel partition fixed in the middle, dividing the cage into two chambers. A hole of $3.5 \mathrm{~cm}$ diameters was made at a height of $7.5 \mathrm{~cm}$ in the center of the cage. Animals were randomly divided into control, positive control and test groups containing 5 mice each. The test groups were treated with extract of $F$. stricta at the doses of 200 and $400 \mathrm{mg} / \mathrm{kg}$ body weight orally whereas the positive control group with diazepam (1 $\mathrm{mg} / \mathrm{kg}$ ) and control group with vehicle (1\% Tween 80 in water). Number of passages of the animals through the hole from one chamber to the other was counted for $5 \mathrm{~min}$ at $0,30,60,90$ and $120 \mathrm{~min}$ after oral administration of the extract as well as diazepam and vehicle [23]. The apparatus was thoroughly cleaned after each trial.

\section{Thiopental sodium induced sleeping time test}

For the experiment, the animals were randomly allocated to four groups, each with 5 mice. The test groups were given the leaf extract of F. stricta at doses of 200 and $400 \mathrm{mg} / \mathrm{kg}$ body weight, while the positive control was treated with diazepam $(1 \mathrm{mg} / \mathrm{kg})$ and control group with vehicle ( $1 \%$ Tween 80 in water). Thirty minutes later, thiopental sodium $(40 \mathrm{mg} / \mathrm{kg}$ ) was administered to each mouse to induce sleep. The animals were observed by placing them on separate chambers for the latent period (time between thiopental administrations to loss of righting reflex) and duration of sleep i.e. time between the loss and recovery of righting reflex. The onset of sleep and total sleeping time were recorded for control, positive control and test groups [24].

\section{Elevated plus maze test}

The method initially suggested by Handley and Mithani were employed with minor modifications [25]. The apparatus consists of two open arms $(5 \times 10) \mathrm{cm}$ and two closed arms $(5$ $\times 10 \times 15) \mathrm{cm}$ radiating from a platform $(5 \times 5) \mathrm{cm}$ to form a plus-sign figure. The apparatus was situated $40 \mathrm{~cm}$ above the floor. The open arms edges were $0.5 \mathrm{~cm}$ in height to keep the mice from falling and the closed-arms edges were $15 \mathrm{~cm}$ in height. Sixty minutes after administration of the test drugs, each animal was individually placed in the center of the EPM and was allowed 5 min 
for free exploration. Next, the number of open and enclosed arm entries, and time spent on open arms was manually registered [26]. Entry into an arm was defined as the point when the animal placed all four paws onto the arm. The percentage of open arm entries (100 × open/total entries) and the percentage of time spent in the open arms $(100 \times$ open/ (open + enclosed) $)$ were calculated for each animal. Observations made from an adjacent corner produced significant $(p<$ $0.05, p<0.01)$ decreases of locomotion from its initial value during the period of the experiment (Table 1). Maximum suppression of locomotor activity was displayed at the dose of $400 \mathrm{mg} / \mathrm{kg}$ body weight, which was comparable to the reference drug diazepam.

\section{Statistical analysis}

The data was expressed as mean \pm standard error of mean (S.E.M.). Statistical comparisons were performed using one-way ANOVA followed by post-hoc Dunnett's test with the SPSS program (SPSS 20.0, USA). The values obtained were compared with the vehicle control group and were considered statistically significant when $* \mathrm{P}<0.05, * * \mathrm{P}<0.01$.

\section{Results}

\section{Neuropharmacological tests}

\section{Open field test}

Open field test of $F$. stricta treated groups (200 and $400 \mathrm{mg} / \mathrm{kg}$ body weight) showed significant and dose-dependent reduction of movement from its initial value at 0 to $120 \mathrm{~min}$ (Table 1). The number of squares traveled by the mice was reduced significantly from its initial value at 0 to $120 \mathrm{~min}$ at the dose level of $200 \mathrm{mg} / \mathrm{kg}$ and $400 \mathrm{mg} / \mathrm{kg}$ body weight $(\mathrm{P}<0.05)$ of the extracts from the leaves of $F$. stricta (Table 1).

Table 1: Effect of extracts of $F$. stricta on exploratory behavior on mice. (Open field test)

\begin{tabular}{|l|l|l|l|l|l|l|}
\hline Treatment & \multirow{2}{*}{$\begin{array}{l}\text { Dose }(\mathrm{mg} \\
\mathbf{k g})\end{array}$} & \multicolumn{5}{|c|}{ No. of Movement } \\
\cline { 3 - 7 } & & $\mathbf{0} \mathrm{min}$ & $\mathbf{3 0} \mathrm{min}$ & $60 \mathrm{~min}$ & $90 \mathrm{~min}$ & $120 \mathrm{~min}$ \\
\hline Control & Vehicle & $116.80 \pm 2.417$ & $91.60 \pm 2.227$ & $61.20 \pm 2.375$ & $47.00 \pm 1.00$ & $49.20 \pm 0.970$ \\
\hline Diazepam & 1 & $71.00 \pm 2.214^{* *}$ & $47.80 \pm 1.281^{* *}$ & $25.40 \pm 0.927^{* *}$ & $\begin{array}{l}20.00 \pm 0.707 \\
* *\end{array}$ & $\begin{array}{l}15.60 \pm 1.288 \\
* *\end{array}$ \\
\hline FSM & 200 & $99.60 \pm 2.112^{* *}$ & $68.60 \pm 1.568^{* *}$ & $37.40 \pm 1.600^{* *}$ & $\begin{array}{l}27.80 \pm 1.068 \\
* *\end{array}$ & $\begin{array}{l}18.40 \pm 1.077 \\
* *\end{array}$ \\
\hline FSM & 400 & $90.20 \pm 1.068^{* *}$ & $60.40 \pm 0.927^{* *}$ & $31.20 \pm 1.281^{* *}$ & $\begin{array}{l}21.80 \pm 0.663 \\
* *\end{array}$ & $\begin{array}{l}16.80 \pm 1.855 \\
* *\end{array}$ \\
\hline FSH & 200 & $106.60 \pm 2.993$ & $66.80 \pm 2.010^{* *}$ & $42.40 \pm 1.860^{* *}$ & $\begin{array}{l}33.60 \pm 1.327 \\
* *\end{array}$ & $\begin{array}{l}26.20 \pm 1.934 \\
* *\end{array}$ \\
\hline FSH & 400 & $94.40 \pm 1.364^{* *}$ & $56.40 \pm 1.288^{* *}$ & $31.80 \pm 1.241^{* *}$ & $\begin{array}{l}27.60 \pm 0.927 \\
* *\end{array}$ & $\begin{array}{l}19.80 \pm 1.020 \\
* *\end{array}$ \\
\hline FSC & 200 & $101.80 \pm 1.828^{* *}$ & $60.00 \pm 2.074^{* *}$ & $37.60 \pm 1.288^{* *}$ & $\begin{array}{l}26.20 \pm 1.241 \\
* *\end{array}$ & $\begin{array}{l}21.80 \pm 0.860 \\
* *\end{array}$ \\
\hline FSC & 400 & $90.60 \pm 1.720^{* *}$ & $52.20 \pm 2.888^{* *}$ & $32.60 \pm 1.568^{* *}$ & $\begin{array}{l}22.60 \pm 1.208 \\
* *\end{array}$ & $\begin{array}{l}19.00 \pm 0.707 \\
* *\end{array}$ \\
\hline
\end{tabular}




\begin{tabular}{|l|l|l|l|l|l|l|}
\hline FSA & 200 & $113.00 \pm 1.517$ & $73.00 \pm 1.517^{* *}$ & $42.00 \pm 2.025^{* *}$ & $\begin{array}{l}30.00 \pm 1.225 \\
* *\end{array}$ & $\begin{array}{l}20.20 \pm 0.860 \\
* *\end{array}$ \\
\hline FSA & 400 & $92.40 \pm 1.364^{* *}$ & $55.60 \pm 0.927^{* *}$ & $35.00 \pm 1.673^{* *}$ & $\begin{array}{l}23.40 \pm 0.748 \\
* *\end{array}$ & $\begin{array}{l}17.80 \pm 0.663 \\
* *\end{array}$ \\
\hline FSE & 200 & $98.20 \pm 1.068^{* *}$ & $54.40 \pm 1.208^{* *}$ & $37.20 \pm 2.557^{* *}$ & $\begin{array}{l}26.00 \pm 2.000 \\
* *\end{array}$ & $\begin{array}{l}21.40 \pm 1.077 \\
* *\end{array}$ \\
\hline FSE & 400 & $83.80 \pm 1.530^{* *}$ & $47.00 \pm 1.304^{* *}$ & $30.40 \pm 1.030^{* *}$ & $\begin{array}{l}23.00 \pm 1.140 \\
* *\end{array}$ & $\begin{array}{l}18.20 \pm 0.800 \\
* *\end{array}$ \\
\hline
\end{tabular}

Values are mean \pm S.E.M., $(\mathrm{n}=5) ;{ }^{*} \mathrm{P}<0.05,{ }^{* *} \mathrm{P}<0.01$, Dunnett's test as compared to control (Vehicle $=0.4 \mathrm{~mL} / \mathrm{mouse}$ ).

\section{Hole cross test}

Hole cross test of $F$. stricta treated groups showed a decrease of movement from its initial value at 0 to $120 \mathrm{~min}$. Results showed in the table (Table 2) suggests that the number of hole crossed from one chamber to another by mice was decreased significantly for all chemical extracts of $F$. stricta leaves compared to the standard drug Diazepam. But, at doses of $400 \mathrm{mg} / \mathrm{kg}(\mathrm{P}<0.05)$, maximum suppression of locomotor activity was displayed which was comparable to the reference drug diazepam (Table 2).

Table 2: Effect of extracts of $F$. stricta on exploratory behavior on mice. (Hole cross test)

\begin{tabular}{|c|c|l|l|l|l|l|}
\hline \multirow{2}{*}{ Treatment } & $\begin{array}{c}\text { Dose } \\
(\mathrm{mg} / \mathrm{kg})\end{array}$ & \multicolumn{5}{|c|}{ No. of Movement } \\
\cline { 3 - 7 } & & \multicolumn{1}{|c|}{$\mathbf{0} \mathrm{min}$} & \multicolumn{1}{|c|}{$30 \mathrm{~min}$} & \multicolumn{1}{|c|}{$60 \mathrm{~min}$} & $90 \mathrm{~min}$ & $120 \mathrm{~min}$ \\
\hline Control & Vehicle & $22.00 \pm 0.707$ & $19.60 \pm 1.435$ & $14.40 \pm 1.030$ & $11.60 \pm 1.208$ & $10.80 \pm 0.583$ \\
\hline Diazepam & 1 & $12.80 \pm 0.735^{* *}$ & $6.00 \pm 0.707^{* *}$ & $5.40 \pm 0.872^{* *}$ & $4.40 \pm 0.510^{* *}$ & $3.80 \pm 0.374^{* *}$ \\
\hline FSM & 200 & $19.60 \pm 0.510$ & $10.60 \pm 0.927^{* *}$ & $8.40 \pm 0.510^{*}$ & $6.20 \pm 0.583^{*}$ & $5.60 \pm 0.812^{* *}$ \\
\hline FSM & 400 & $16.00 \pm 0.707^{* *}$ & $8.80 \pm 0.663^{* *}$ & $6.00 \pm 1.00^{* *}$ & $5.20 \pm 0.735^{*}$ & $4.60 \pm 0.727^{* *}$ \\
\hline FSH & 200 & $23.40 \pm 1.077$ & $18.00 \pm 1.000$ & $8.80 \pm 0.583^{*}$ & $7.60 \pm 0.678$ & $5.80 \pm 0.735^{* *}$ \\
\hline FSH & 400 & $17.80 \pm 0.800^{*}$ & $10.00 \pm 0.707^{* *}$ & $6.80 \pm 0.735^{* *}$ & $5.20 \pm 0.374^{*}$ & $5.00 \pm 0.632^{* *}$ \\
\hline FSC & 200 & $20.20 \pm 0.860$ & $16.40 \pm 0.600$ & $7.60 \pm 0.510^{* *}$ & $6.00 \pm 0.707^{*}$ & $5.60 \pm 0.812^{* *}$ \\
\hline FSC & 400 & $17.40 \pm 0.927^{*}$ & $9.80 \pm 0.860^{* *}$ & $5.20 \pm 0.583^{* *}$ & $4.60 \pm 0.510^{*}$ & $4.40 \pm 0.358^{* *}$ \\
\hline FSA & 200 & $20.80 \pm 1.068$ & $16.80 \pm 0.735$ & $9.60 \pm 0.510^{*}$ & $6.00 \pm 0.316^{*}$ & $5.40 \pm 0.927^{* *}$ \\
\hline FSA & 400 & $17.20 \pm 0.583^{* *}$ & $11.40 \pm 0.510^{*}$ & $7.20 \pm 0.374^{* *}$ & $5.00 \pm 0.707^{*}$ & $4.20 \pm 0.522^{* *}$ \\
\hline FSE & 200 & $22.40 \pm 1.568$ & $13.20 \pm 0.970^{*}$ & $7.80 \pm 0.663^{* *}$ & $6.00 \pm 1.789^{*}$ & $5.60 \pm 1.077^{*}$ \\
\hline FSE & 400 & $18.00 \pm 1.000$ & $9.40 \pm 0.510^{* *}$ & $5.60 \pm 0.510^{* *}$ & $5.80 \pm 1.158^{*}$ & $4.40 \pm 0.669^{* *}$ \\
\hline
\end{tabular}

Values are mean \pm S.E.M., $(\mathrm{n}=5) ;{ }^{*} \mathrm{P}<0.05, * * \mathrm{P}<0.01$. Dunnett's test as compared to control (Vehicle $=0.4 \mathrm{~mL} / \mathrm{mouse}$ ).

\section{Thiopental sodium induced sleeping time test}

In the thiopental induced hypnosis test, the extract at doses, 200 and $400 \mathrm{mg} / \mathrm{kg}$ showed a significant reduction in the time of onset of sleep in a dose-dependent manner; mostly in the case of methanol and ethanol extract of $F$. stricta leaves (Table 3). The effect of the extract (200 and $400 \mathrm{mg} / \mathrm{kg}$ ) on the onset of sleep was comparable to that of standard drug Diazepam. Both doses 
of the extract potentiated the duration of thiopental sodium induced sleeping time in test animals compared to controls (Table 3).

Table 3: Effect of extracts of $F$. stricta on thiopental sodium induced sleeping time

\begin{tabular}{|c|c|c|c|}
\hline Treatment & Dose(mg/kg) & Onset of sleep(min) & Duration of sleep(min) \\
\hline Control & Vehicle & $42.50 \pm 1.059$ & $47.70 \pm 0.574$ \\
\hline Diazepam & 1 & $13.88 \pm 1.151^{* *}$ & $142.14 \pm 3.075^{* *}$ \\
\hline FSM & 200 & $13.70 \pm 1.537^{* *}$ & $97.86 \pm 4.853^{* *}$ \\
\hline FSM & 400 & $7.66 \pm 0.731^{* *}$ & $119.00 \pm 4.226^{* *}$ \\
\hline FSH & 200 & $16.98 \pm 0.664^{* *}$ & $85.78 \pm 3.229^{* *}$ \\
\hline FSH & 400 & $10.64 \pm 0.670^{* *}$ & $101.06 \pm 1.997^{* *}$ \\
\hline FSC & 200 & $15.84 \pm 0.828^{* *}$ & $89.26 \pm 2.839^{* *}$ \\
\hline FSC & 400 & $10.04 \pm 0.451^{* *}$ & $103.06 \pm 1.492^{* *}$ \\
\hline FSA & 200 & $15.34 \pm 1.332^{* *}$ & $109.00 \pm 3.730^{* *}$ \\
\hline FSA & 400 & $11.98 \pm 0.828^{* *}$ & $126.42 \pm 3.441^{* *}$ \\
\hline FSE & 200 & $13.16 \pm 0.832^{* *}$ & $112.20 \pm 2.663^{* *}$ \\
\hline FSE & 400 & $5.66 \pm 0.510^{* *}$ & $126.20 \pm 3.097^{* *}$ \\
\hline
\end{tabular}

Values are expressed as mean \pm S.E.M, $(\mathrm{n}=4-5) ; * \mathrm{P}<0.05$, $* * \mathrm{P}<0.01$, Dunnett's test as compared to control (Vehicle $=0.4 \mathrm{~mL} / \mathrm{mouse}$ ).

\section{Elevated plus maze test}

In the EPM, the behavior of mice model, as observed, confirmed the anxiolytic activity of diazepam as reported previously. The extracts of $F$. stricta at the dose of $400 \mathrm{mg} / \mathrm{kg}(\mathrm{P}<0.01)$, significantly increased the percentage of entries of mice into the open arms, and the percentage of time spent in the open arms of the EPM as shown in Table 4. The effects of treatment of mice at the dose of $200 \mathrm{mg} / \mathrm{kg}$ on open arm entries and time spent in open arms were dose dependent. The number of closed arm entries and time spent in the closed arms was decreased significantly in the extract treated groups which were comparable with the standard diazepam.

Table 4: Effect of extracts of $F$. stricta on EPM test during 5 min test session.

\begin{tabular}{|c|c|c|c|}
\hline Treatment & Dose(mg/kg) & \% Entry into open arm & $\begin{array}{c}\text { \% time spent in open } \\
\text { arm }\end{array}$ \\
\hline Control & Vehicle & $35.69 \pm 1.244$ & $35.02 \pm 1.181$ \\
\hline Diazepam & 1 & $71.98 \pm 1.090^{* *}$ & $73.29 \pm 1.457^{* *}$ \\
\hline FSM & 200 & $43.87 \pm 1.215^{* *}$ & $46.19 \pm 1.217^{* *}$ \\
\hline FSM & 400 & $58.12 \pm 2.037^{* *}$ & $58.65 \pm 2.252^{* *}$ \\
\hline FSH & 200 & $38.40 \pm 1.085$ & $37.95 \pm 0.914$ \\
\hline FSH & 400 & $56.09 \pm 0.577^{* *}$ & $55.74 \pm 0.794^{* *}$ \\
\hline
\end{tabular}




\begin{tabular}{|c|c|c|c|}
\hline FSC & 200 & $36.91 \pm 1.493$ & $40.05 \pm 0.609^{*}$ \\
\hline FSC & 400 & $58.48 \pm 1.886^{* *}$ & $58.24 \pm 1.130^{* *}$ \\
\hline FSA & 200 & $42.35 \pm 1.030^{*}$ & $43.11 \pm 0.558^{* *}$ \\
\hline FSA & 400 & $60.76 \pm 1.324^{* *}$ & $61.49 \pm 1.230^{* *}$ \\
\hline FSE & 200 & $42.25 \pm 1.446^{*}$ & $44.41 \pm 0.442^{* *}$ \\
\hline FSE & 400 & $62.84 \pm 0.855^{* *}$ & $61.96 \pm 2.346^{* *}$ \\
\hline
\end{tabular}

Values are expressed as mean \pm S.E.M., $(\mathrm{n}=5) ; * \mathrm{P}<0.05$, $* * \mathrm{P}<0.01$, Dunnett's test as compared to control (Vehicle $=0.4 \mathrm{~mL} / \mathrm{mouse}$ ).

\section{Discussion}

The result of open field and hole cross tests showed that the studied plant decreased the frequency as well as the bountifulness of movements. Since the level of excitability of the CNS is measured by locomotor activity, this reduction in spontaneous motor activity that could be considered as the sedative effect of the plant extracts. Locomotor activity lowering effect was evident at the 2 nd observation (30 min) and continued up to the $5^{\text {th }}$ observation period (120 min). So in addition, the study on locomotor activity, as measured by hole cross and open field tests, it can be stated that both doses of chemical extracts of $F$. stricta leaves decreased the frequency and the amplitude of movements. The above result also showed that crude extracts of $F$. stricta plant had strong sedative and hypnotic action that principally mediated in the CNS by the $\mathrm{GABA}_{\mathrm{A}}$ receptor complex. Thiopental, a barbiturate drug, produce sedative-hypnotic result at a certain dose due to their interaction with $\mathrm{GABA}_{\mathrm{A}}$ receptors which enhance the GABAergic transmission. It potentiates GABA activity, entering chloride into the neuron by prolonging the duration of chloride channel opening. On the other hand, thiopental can inhibit excitatory glutamate receptors. All of these molecular action lead to decrease of neuronal activity that supports the following reference substances which possess sedative action.

Substances which possess CNS depressant activity either decrease the time for the onset of sleep or prolong the duration of sleep or both [27, 28]. The method employed for this assay is considered as a very sensitive way to detect agents with CNS depressant activity [29]. The sedative effect recorded here may be linked to an interaction with benzodiazepines and related compounds that bind to receptors in the CNS and have already been identified in certain plant extracts. So the plant extract of $F$. stricta may contain alkaloids, glycosides, cardiac-glycosides, flavonoids, steroids, tannins, anthraquinone glycosides and saponins. The EPM is one of the most widely validated tests when the test drug increases open arms entries without altering the total number of arm entries and is highly sensitive to the influence of both anxiolytic and anxiogenic drugs acting at the gamma aminobutyric acid type A (GABAA) - benzodiazepine complex [30]. In EPM, normal mice will generally prefer to spend much of their allotted time in the closed arms. This preference appears to reflect an aversion towards open arms that are generated by the fears of the open spaces. Drug like diazepam that increases open arm exploration is considered as anxiolytic and the reverse holds true for anxiogenics [31]. In this 
study, we observed that the administration of different doses (200 and $400 \mathrm{mg} / \mathrm{kg}$ body weight) of extracts of $F$. stricta induced an anxiolytic-like effect in mice, as it increased open arm entries and the time spent in the open arms of the EPM when compared to the control animals.

\section{Conclusion}

All of the results were dose-dependent and statistically significant. Analyzing the results of the present study, it can be inferred that the crude extracts of $F$. stricta possess significant neuropharmacological activity. Therefore, we can suggest that the extract may fulfill the therapeutic need for the treatment of anxiety and related neuropsychiatric disorders. However, further investigation is necessary to determine the exact phyto-constituents and mechanism of action that are responsible for the biological activities of the leaf extracts of $F$. stricta.

\section{Abbreviations}

F. stricta: Flemingia stricta; EPM: Elevated plus maze; GABA: Gamma-aminobutyric acid; CNS: Central nervous System, FSM: F. stricta Methanol, FSH: F. stricta N-hexane, FSC: $F$. stricta Chloroform, FSA: F. stricta Aqueous, FSE: F. stricta Ethanol.

\section{Competing interests}

The authors declare that they have no competing interests.

\section{Ethical approval}

The set of rules followed for animal experiment were approved by the institutional animal ethics committee, Department of Pharmacy, International Islamic University Chittagong, Bangladesh according to governmental guidelines. Pharmacy P\&D 59/04-10.

\section{Consent for publication}

All authors read and approved the final content of this manuscript for publication.

\section{Authors' contributions}

MSB, MNA and MMR proposed and designed the study. MSB, MNA and MJB conducted all laboratory experiments; MNA, MSB and MRI analyzed and interpreted experimental results as well as participated in manuscript preparations.

\section{Acknowledgement}

The authors wish to thank Botanist Dr. Shaikh Bokhtear Uddin, Professor, Department of Botany, University of Chittagong, Bangladesh, who helped to identify the plant. We would like to express our gratitude to the authority of the International Centre for Diarrheal Disease and Research, Bangladesh (ICDDRB) for providing the experimental mice. The authors are also grateful to the Department of Pharmacy, International Islamic University Chittagong, Chittagong, Bangladesh, for providing research facilities. 


\section{References}

1. Chew AL, Jessica JJA, Sasidharan S. Antioxidant and antibacterial activity of different parts of Leucas aspera. Asian Pac J Trop Biomed. 2012; 2(3):176-180.

2. Buller R, Legrand V. Novel treatments for anxiety and depression: hurdles in bringing them to the market. Drug Discov Today. 2001; 6:1220-1230.

3. Yadav AV, Kawale LA, Nade VS. Effect of Morus alba L. (mulberry) leaves on anxiety in mice. Indian J Pharmacol. 2008; 40:32-36.

4. Titov N, Andrews G, Kemp A, Robinson E. Characteristics of adults with anxiety or depression treated at an internet clinic: comparison with a national survey and an outpatient clinic. PLOS ONE. 2010; 5(5):e10885.

5. Woode E, Abotsi WK, Mensah AY. Anxiolytic-and antidepressant-like effects of an ethanolic extract of the aerial parts of Hilleria latifolia (Lam.) H. Walt. in mice. J Nat Pharm. 2011; 2:62-71.

6. Katzung B: Basic and clinical pharmacology. 6th ed. California: Prentice-Hall International In. 1994, p. 323.

7. Rabbani M, Sajjadi SE, Mohammadi A. Evaluation of the anxiolytic effect of Nepeta persica Boiss. in mice. Evid-Based Complement Alternat Med. 2008; 5(2):181-186.

8. Rang HP, Dale MM, Ritter JM: Pharmacology. 3rd ed. London: Churchill Livingstone Inc.; 1996, p. 512.

9. Clark WG, Brater DC, Johnscn AR. Goth's medical pharmacology. 12th ed. New Delhi: Galgotia Publication Pvt. Ltd. 1989, p. 288.

10. Essig CF. Addiction to nonbarbiturate sedative and tranquilizing drug. Clin Pharmacol Ther. 1964; 5:334-343.

11. Isbell H, Fraser HF. Addiction to analgesics and barbiturates. J Pharmacol Exp Ther. 1950; 99(4:2):355-397.

12. O'Brien CP. Drug addiction and drug abuse. In: Brunton L, Chabner B, Knollman B, editors. Goodman and Gilman's the pharmacological basis of therapeutics. 9th ed. New York: McGraw-Hill Professional; 1996, p. 570.

13. Tripathi KD. Essential medical pharmacology. 3rd ed. New Delhi: Jaypee Brothers Medical Publishers; 1994, p. 324.

14. Schuckit MA. A low level of response to alcohol as a predictor of future alcoholism. Am J Psychiatry. 1994; 151:184-189. 
15. Hook f. Flemingia stricta Roxb. Fl Ind 1832; 3:342.

16. http://www.legumes-online.net/ildis/aweb/td076/td_16024.htm.

17. Motaleb MA, Hossain MK, Alam MK, Mamun MA, Sultana M. Commonly used medicinal herbs and shrubs by traditional herbal practitioners Glimpses from Thanchi upazila of Bandarban, p.88-89.

18. Rahman MA, Uddin SB, Wilcock CC. Medicinal Plants used by Chakma Tribe in Hill Tracts Districts of Bangladesh. Indian Journal of Traditional Knowledge 2007; 6(3): 508517.

19. Uddin SN. Traditional Uses of Ethnomedicinal Plants of the Chittagong Hill Tracts. Bangladesh National Herbarium, Bangladesh 2006. p 992.

20. Khisha T, Karim R, Chowdhury SR, Banoo R. Ethnomedical Studies of Chakma Communities of Chittagong Hill Tracts, Bangladesh. Bangladesh Pharmaceutical Journal 2012; 15(1):59-67.

21. Tiwari P, Kumar B, Kaur M, Kaur G, Kaur H. Phytochemical screening and extraction: a review. Int Pharm Sci. 2011;1:98-106.

22. Gupta BD, Dandiya PC, Gupta ML. A psychopharmacological analysis of behavior in rat. Jpn J Pharmacol. 1971; 21:293.

23. Takagi K, Watanabe M, Saito H. Studies on the spontaneous movement of animals by the hole cross test; effect of 2-dimethylaminoethanol and its acyl esters on the central nervous system. Jpn J Pharmacol. 1971; 21:797-810.

24. Ferrini R, Miragoli G, Taccardi B. Neuro-pharmacological studies on SB 5833, a new psychotherapeutic agent of the benzodiazepine class. Arzneim-Forsch (Drug Res) 1974; 24:2029-2032.

25. Lister RG. The use of a plus-maze to measure anxiety in the mouse. Psychopharmacology (Berl). 1987; 92:180-185.

26. Pellow S, File SE. Anxiolytic and anxiogenic drug effects on exploratrory activity in an elevated plus-maze: A novel test if anxiety in rat. Pharmacol Biochem Behav. 1986; 24:525-529.

27. Raquibul Hasan SM, Hossain MM, Akter R, Jamila M, Mazumder EHM, Rahman S. Sedative and anxiolytic effects of different fractions of the Commelina benghalensis Linn. Drug Discov Ther. 2009; 3:221-227. 
28. Sen AK, Bose S, Dutta SK. Comparative evaluation of CNS depressant activity of the flavonoid fractions from the fresh leaves and flowers of Ixora coccinea Linn. J Pharma Sci Tech. 2011; 1(1):54-56.

29. Hossain MM, Biva IJ, Jahangir R, Vhuiyan MMI. Central nervous system depressant and analgesic activity of Aphanamixis polystachya (Wall.) parker leaf extract in mice. Afr J Pharm Pharmacol. 2009; 3(5):282-286.

30. Dhonnchadha BAN, Bourin M, Hascoet M. Anxiolytic-like effects of 5-HT2 ligands on three mouse models of anxiety. Behav Brain Res. 2011; 140:203-214.

31. Subramanian N, Jothimanivannan C, Kumar RS, Kameshwaran S. Evaluation of antianxiety activity of Justicia gendarussa burm. Pharmacologia. 2013; 4(5):404-407. 